\title{
Early Neonatal Experience of Long-Evans Rats Results in Long-lasting Changes in Reactivity to a Novel Environment and Morphine-induced Sensitization and Tolerance
}

\author{
Mikhail Kalinichev, Ph.D., Keith W. Easterling, Ph.D., and Stephen G. Holtzman, Ph.D.
}

In Long-Evans rats, daily 3-h separation from the dam during the neonatal period results in enduring alterations in behavioral and neuroendocrine responses to stressors and sensitivity to antinociceptive effects of acute and chronic morphine. We tested whether early neonatal experience alters sensitivity to effects of morphine on locomotor activity. The subjects were adult rats that had one of the following backgrounds: daily separation from the dam on postnatal days 2-14 for either $3 \mathrm{~h}$ (maternal separation (MS)) or 15 min (handled control (H)) or no separation from the dam (non-handled control (NH)). After two consecutive days of baseline activity measurements, subjects were tested daily after SC injections of either morphine $(10 \mathrm{mg} / \mathrm{kg})$ or saline for seven days and again on day 10. Beginning five days later, saline and $1.0-10 \mathrm{mg} / \mathrm{kg}$ of morphine were tested in all animals. On the baseline days, MS animals had higher horizontal and vertical activity than did $\mathrm{NH}$ controls, whereas $\mathrm{H}$ animals spent more time in the center of the testing chamber. In MS and $\mathrm{H}$ animals but not in $\mathrm{NH}$ controls, daily injections of morphine produced progressive increases in all locomotor activity measures, indicative of sensitization (horizontal counts, center time) and tolerance (vertical counts). MS animals with a history of morphine treatment had significantly higher horizontal and vertical activity after a saline injection than did their counterparts with a history of saline treatment, indicative of conditioning. They also exhibited greater locomotor sensitization to $1.0 \mathrm{mg} / \mathrm{kg}$ of morphine than did $\mathrm{H}$ and $\mathrm{NH}$ controls. These results provide further evidence that environmental manipulation in the form of maternal separation early in life results in enduring changes in sensitivity to effects of morphine that could reflect altered endogenous opioid systems.

[Neuropsychopharmacology 27:518-533, 2002]

(C) 2002 American College of Neuropsychopharmacology.

Published by Elsevier Science Inc.
From the Department of Pharmacology, Emory University School of Medicine, Rollins Research Center, 1510 Clifton Road, Suite 5074, Atlanta, GA 30322

Address correspondence to: Mikhail Kalinichev, Ph.D., Department of Pharmacology, Emory University School of Medicine, Rollins Research Center, 1510 Clifton Road, Suite 5074, Atlanta, GA 30322. Tel.: 404-727-0359; Fax: 404-727-0365; E-mail: mkalini@ emory.edu

Received October 31, 2001; revised February 20, 2002; accepted February 27, 2002.

Online publication: 3/1/02 at www.acnp.org/citations/ Npp030102256.
KEY WORDS: Maternal separation; Opioids; Morphine; Conditioning; Mesolimbic; Dopamine

There is growing evidence that repeated exposure to stress early in life results in profound changes in the brain, some of which appear to be long lasting and possibly permanent. In humans, early stress in the form of childhood abuse and neglect has been associated with increases in stress-reactivity and vulnerability to several psychiatric disorders and substance abuse later in adult life (Petitto et al. 1992; Servant and Parquet 1994; 
Arellano 1996; Duncan et al. 1996; Young et al. 1997; Heim et al. 1997; Bernet and Stein 1999; Widom 1999; Heim et al. 2000). It has been hypothesized that a stress-responsive neural network, permanently altered as a result of early stress, is a key component in the development of psychopathology later in adulthood (Heim et al. 1997, 2000).

Enduring increases in behavioral and neuroendocrine responsiveness to stress as a result of early trauma have been successfully modeled in the rat by the procedure of maternal separation, where neonatal rats are removed from the mother for several hours daily during the first two weeks of life (Plotsky and Meaney 1993; Wigger and Neumann 1999; Caldji et al. 2000; Huot et al. 2001; Kalinichev et al. 2001a,b, 2002). When tested as adults, maternally separated (MS) animals exhibit a wide array of behavioral and neuroendocrine changes similar to those observed in patients with depression and anxiety disorders (Amsterdam et al. 1987; Heit et al. 1997; Ladd et al. 2000). For example, MS males and MS females are less likely to explore open arms of the plus-maze and they spend less time on these arms compared with non-handled $(\mathrm{NH})$ animals (Wigger and Neumann 1999; Huot et al. 2001; Kalinichev et al. 2002). MS males also exhibit exaggerated auditory startle responses (Kalinichev et al. 2002) and when food deprived, are less likely to approach food in a novel arena (Caldji et al. 2000). In MS males there is an increase in basal CRF levels (Plotsky and Meaney 1993) as well as in stress-induced levels of corticosterone, ACTH and CRF (Liu et al. 2000; Huot et al. 2001; Kalinichev et al. 2002), indicative of hypersensitivity of the HPA axis to stress.

There is evidence that the procedure of maternal separation in the rat also can be used to model the increase in vulnerability to substance abuse that has been described in many patients who had experienced significant physical or emotional traumas in childhood (Ireland and Widom 1994; Triffleman et al. 1995; Medrano et al. 1999). Research from our and other laboratories indicates that maternal separation during the neonatal period results in robust and enduring changes in sensitivity to alcohol and other abused drugs, including opioids (Zimmerberg and Shartrand 1992; Matthews et al. 1996, 1999; Kehoe et al. 1998a; Campbell and Spear 1999; Kosten et al. 2000; Huot et al. 2001; Kalinichev et al. 2001a,b).

Opioid receptors and their endogenous ligands are detectable in the rat brain as early as mid gestation and are likely to serve a neurotrophic function during this period (Hauser and Stiene-Martin 1993). The first few weeks of neonatal life are marked with a significant developmental reorganization in the opioid systems. For example, the distributions and contents of $\beta$-endorphin and enkephalin alter or fluctuate in several brain regions (Bayon et al. 1979; Tsang et al. 1982). Also, during the first few weeks of life, the numbers of $\mu$ - and $\kappa$ binding sites increase substantially, before declining to adult levels afterwards (Spain et al. 1985; Petrillo et al. 1987). Furthermore, the major increase in $\delta$ receptor ex- pression occurs after the first postnatal week (Spain et al. 1985; Petrillo et al. 1987). The robust expression/fluctuations in these systems during the neonatal period are likely to be linked to the changes in essential behavioral functions that opioids regulate during this period, such as suckling, social bonding and separation distress (Barr 1993). Perhaps the opioid systems in neonates are particularly vulnerable for environmental perturbations that alter or interfere with these behaviors.

In this study, we continued to investigate the possible link between neonatal maternal separation and enduring changes in opioid systems. We assessed the morphine-induced neuroadaptive phenomena of behavioral sensitization and tolerance to effects of morphine on locomotor activity in adult Long-Evans male rats that had experienced either prolonged, brief or no separations from the mother during the neonatal period. In the rat, repeated intermittent injection of morphine results in a decrease in the locomotor-suppressant action of the drug, referred to as tolerance, and in an enhancement of the locomotor-stimulant action, referred to as behavioral sensitization (Babbini and Davis 1972; Brady and Holtzman 1981; Bartoletti et al. 1983; Kalivas and Stewart 1991; Stewart and Badiani 1993; Rauhala et al. 1995; Powell and Holtzman 2001). Morphine-induced tolerance and sensitization are mediated by $\mu$ - and $\delta$-opioid receptors and appear to be long-lasting (Babbini et al. 1975; Spanagel et al. 1993; Powell and Holtzman 2001). It has been suggested that the complex neuroadaptations that are reflected in behavioral sensitization play an important role in the development of drug-seeking, drug-taking, and relapse behaviors that characterize addiction (Wise and Bozarth 1987; Robinson and Berridge 1993; Berridge and Robinson 1995). Therefore, studying behavioral sensitization in animals that experienced maternal separation might provide a better understanding of the environmental factors that can alter an organism's vulnerability to drug abuse.

\section{METHODS}

\section{Subjects}

The subjects were male Long-Evans hooded rats (BlueSpruce, Harlan Sprague Dawley Inc., Indianapolis, IN) approximately 120 days of age at the time of testing. A total of 47 subjects were used in this study. All the subjects were the offspring of dams that were shipped to our facility on the $12^{\text {th }}$ day of pregnancy. The pups were born and raised in our colony. Food and water were always available ad libitum. The colony room was maintained on a 12:12 light-dark cycle with lights on at 7 A.M. This study was performed in full accordance with the 1996 Guide for the Care and Use of Laboratory Animals (National Academy of Sciences) and the research protocol was approved by the Institutional Animal Care and Use Committee of Emory University. 


\section{Maternal Separation Procedure}

We used a well documented procedure for neonatal maternal separation (Figure 1) that results in robust group differences in behavioral and neuroendocrine indices of stress-reactivity (Plotsky and Meaney 1993; Wigger and Neumann 1999; Caldji et al. 2000; Liu et al. 2000; Huot et al. 2001; Kalinichev et al. 2002) as well as in sensitivity to acute and chronic morphine (Kalinichev et al. 2001a,b) when animals are tested as adults.

Pups that composed 30 original litters were taken from their dams, and then randomly redistributed among foster dams on postnatal day (PND) 2 (date of birth = PND 1) as all-male (8 pups) litters (7 litters/separation group; Plotsky and Meaney 1993). In the maternal separation procedure the entire litter was removed from the foster dam, who remained in the home cage, and placed into a bedding-lined plastic container in an incubator (Veterinary water-lined warmer, ThermoCare Inc., Incline Village, NE) maintained at $31^{\circ} \mathrm{C}$. Maternally separated litters (MS) were kept in the incubator for $3 \mathrm{~h}$ and then returned to their foster dam. This occurred daily between 9 A.M. and noon on PND 2-14 (Figure 1). Handled $(\mathrm{H})$ group animals experienced a similar procedure; however, the pups remained away from their foster dam for only $15 \mathrm{~min}$. Non-handled $(\mathrm{NH})$ group animals were returned to the foster dam immediately after group assignment (PND 2) and left undisturbed until weaning. After all pups were weaned on PND 22 they were housed in same-treatment group cages. No more than two animals raised by the same foster dam were used in each experimental group.

\section{Locomotor Apparatus}

Eight Omnitech Digiscan Activity Monitors (Omnitech Electronics Inc. Columbus, $\mathrm{OH}$ ), equipped with the VersaMax software (Version 1.30, Omnitech Electronics Inc.) were used to measure locomotor activity. Each animal was tested in an acrylic box $(40 \times 40 \mathrm{~cm})$ surrounded by a framework of photobeams inside a ventilated, soundattenuating cubicle, that was illuminated by fluorescent light. The photobeams were mounted in a $16 \times 16$ beam array around the bottom of the box and $2.5 \mathrm{~cm}$ from the floor. Sixteen additional photobeams were installed $10.5 \mathrm{~cm}$ above the bottom photobeams on the left and right sides of the box in order to measure vertical locomotor activity (i.e., rearing behavior). Locomotor movements were determined by breaks in photobeams and were converted into locomotor activity counts with the aid of the software VersaDat (Version 1.3; Omnitech Electronics Inc.) that was interfaced with a microcomputer.

Automated calculation of several measures of motor activity was provided by this system. Out of these we analyzed two key, mutually exclusive, behaviors: horizontal activity counts (ambulation) and vertical activity counts (rearing). Ambulation and rearing have been used widely as reliable and valuable measures of locomotor activity in the rat (Ivinskis 1970; Walsh and Cummins 1976). It is believed that these behaviors reflect a stable individual trait (i.e., "nonspecific excitability level") that correlates with hippocampal slow wave activity in the rat (Walsh and Cummins 1976). In addition, time spent in the center of locomotor arenas (i.e., away from the walls) was analyzed as an index of emotionality in the rat (Valle 1970; Harro 1993; Kalinichev et al. 2000).

\section{Locomotor Tolerance/Sensitization (Induction Phase)}

The baseline locomotor activity was measured for $2 \mathrm{~h}$ daily on two consecutive baseline days (B1 and B2). Twenty-four to $48 \mathrm{~h}$ after the second baseline session

\section{Maternal Separation protocol}

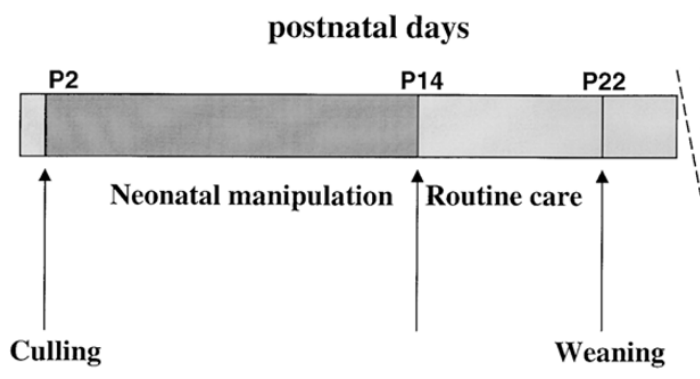

\section{Morphine sensitization/tolerance}

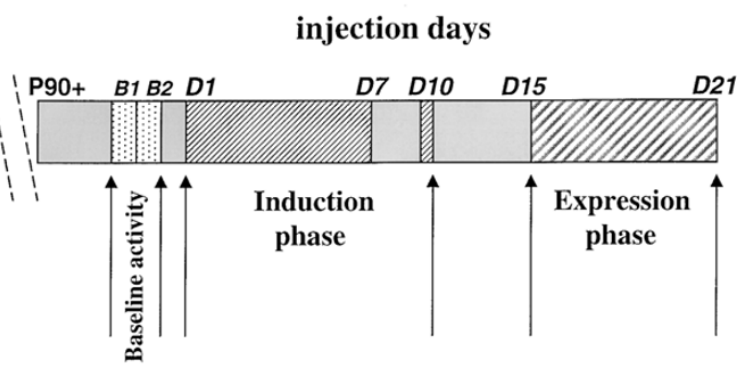

Figure 1. The time-line of the maternal separation and morphine-induced sensitization/tolerance procedures. Neonatal manipulations were performed on postnatal days (P) 2-14 (see the text). As adults (90+ days old), animals were tested for baseline activity on two consecutive days (B1, B2). During the induction phase (D1-10) they were injected with either 10 $\mathrm{mg} / \mathrm{kg}$ of morphine or saline on D1-D7 and D10. During the expression phase (D15-21) all rats were given saline, 1.0, 3.0, and $10 \mathrm{mg} / \mathrm{kg}$ morphine on D15, D17, D19, and D21, respectively, and activity was tested after each injection. 
(injection day 1) animals were placed in the locomotor boxes for 2-h sessions immediately after receiving an injection of either $10 \mathrm{mg} / \mathrm{kg}$ of morphine (Morphine group) or saline (Saline group). Three $\mathrm{NH}$ animals died after receiving the first injection of $10 \mathrm{mg} / \mathrm{kg}$ of morphine. Injections continued daily for seven days (Figure 1 ). On days 3, 5, and 7, animals were injected just before being placed in the locomotor boxes for a 2-hour session. On days 2, 4, and 6, animals received the appropriate injection in the home cage. On day 10, after a 2-day break from injections and testing, the group-appropriate injections were given just before a 2 -h test session.

\section{Locomotor Tolerance/Sensitization (Expression Phase)}

A morphine-dose response curve (Sal, 1.0, 3.0, $10 \mathrm{mg} / \mathrm{kg}$ ) was determined in all animals across days 15, 17, 19 and 21 (Figure 1). The animals received no injections or tests on days 11-14, 16, 18, and 20.

\section{Drug}

Morphine sulfate (Penick, Newark, NJ) was dissolved in saline and administered SC in a volume of $1.0 \mathrm{ml} / \mathrm{kg}$ body weight. All doses are expressed as the free base.

\section{Data Analysis}

A repeated measures or factorial analysis of variance (ANOVAs) was used to determine if there was a significant main effect. Dunnett's (for comparisons with a single mean) and Fisher's protected least significant difference post hoc tests were used for multiple comparisons. The $\alpha$ level chosen was $p \leqslant .05$.

\section{RESULTS}

\section{Locomotor Activity in a Novel Environment}

Horizontal Activity. During the 2-h session of baseline activity on day 1 of testing, there was a significant decline of horizontal activity over time $\left(\mathrm{F}_{7,308}=336.81\right.$, $p<.0001$; Figure 2, panel a). There was a significant main effect of neonatal experience $\left(\mathrm{F}_{2,308}=7.01, p<.01\right.$; Figure 2, panel b), but no significant Time $X$ Experience interaction. The total number of horizontal counts over $2 \mathrm{~h}$ by $\mathrm{MS}$ and $\mathrm{H}$ groups was significantly higher $\left(\mathrm{F}_{2,44}=\right.$ 6.80, $p<.01$ ) compared with NH animals (Figure 2, panel b).

Vertical Activity. On baseline day 1 vertical activity declined significantly over $2 \mathrm{~h}$ of testing $\left(\mathrm{F}_{7,308}=113.74\right.$, $p<.0001$; Figure 2, panel c). There was a significant main effect of neonatal experience $\left(\mathrm{F}_{2,308}=7.70, p=\right.$ .001), and a significant Time $X$ Experience interaction
$\left(\mathrm{F}_{2,308}=8.21, p<.0001\right)$. The total number of vertical activity counts over the $2 \mathrm{~h}$ period was significantly higher in MS animals $\left(\mathrm{F}_{2,44}=5.96, p<.01\right)$ compared with NH controls (Figure 2, panel d).

Time in the Center of the Testing Arena. During the 2-h session of baseline activity on day 1 the center time declined significantly over time $\left(\mathrm{F}_{7,308}=17.53, p<.0001\right.$; Figure 2, panel e). There was a significant main effect of neonatal experience $\left(\mathrm{F}_{2,308}=5.53, p<.001\right)$, and a significant Time X Experience interaction $\left(\mathrm{F}_{2,308}=1.82, p<\right.$ .05). The total time spent in the center by $\mathrm{H}$ animals was significantly higher compared with $\mathrm{MS}$ and $\mathrm{NH}$ animals $\left(\mathrm{F}_{2,44}=5.82, p<.01\right.$; Figure 2, panel $\left.\mathrm{f}\right)$.

\section{Induction Phase of Locomotor Tolerance/Sensitization}

Horizontal Activity. Activity counts declined over two days (B1, B2) of baseline activity (Figure 3, panels $\mathrm{a}-\mathrm{c}$ ). On day 1 of treatment, activity of animals receiving saline declined even further. Daily injections of 10 $\mathrm{mg} / \mathrm{kg}$ of morphine during the induction phase of sensitization produced a pattern of changes in horizontal activity that was largely similar for MS and $\mathrm{H}$ rats, but different for $\mathrm{NH}$ rats. In particular, in $\mathrm{MS}$ and $\mathrm{H}$ animals, but not in NH controls, initial injections of $10 \mathrm{mg} / \mathrm{kg}$ of morphine suppressed horizontal activity in comparison with saline-treated animals (Figure 3, panels $\mathrm{a}-\mathrm{c}$ ). Continued injections of morphine resulted in a progressive increases in horizontal counts by $\mathrm{MS}$ and $\mathrm{H}$ animals, but not by NH controls (Figure 3, panels a-c): by day $5(\mathrm{H})$ or day 10 (MS) horizontal counts exceeded significantly those on day 1 (Figure 3 , panels a-c).

For morphine-exposed animals, there was a significant main effect of days $\left(\mathrm{F}_{2,72}=10.14 ; p<.0001\right)$ and a significant Days $X$ Neonatal experience interaction $\left(\mathrm{F}_{8,72}=\right.$ 2.66; $p<.05)$. For saline treated animals, there was a significant Days $X$ Neonatal experience interaction $\left(\mathrm{F}_{8,84}=\right.$ 8.82; $p<.0001)$. Planned comparisons revealed that on day 10 of treatment the horizontal activity of morphineexposed MS and $\mathrm{H}$ animals was 140-170\% higher than that of the corresponding saline-treated groups $(\mathrm{t}>$ 1.99; df $=1 ; 14, p<.05$; Figure 3, panels a, b). In sharp contrast, morphine-exposed $\mathrm{NH}$ animals tended to be less active than their saline-exposed counterparts (Figure 3, panel c).

The time-course comparisons of the groups on treatment days 1 and 10 are presented on Figure 3, panels $\mathrm{d}-\mathrm{g}$. On day 1 of treatment morphine-exposed animals were less active than saline-exposed controls throughout the 2-h session, even though the differences were small (Figure 3, panels d, e). By day 10, the activity of morphine-exposed MS and $\mathrm{H}$ animals increased substantially, exceeding levels of saline-treated controls throughout the 2-h session, but in particular during the first 15 

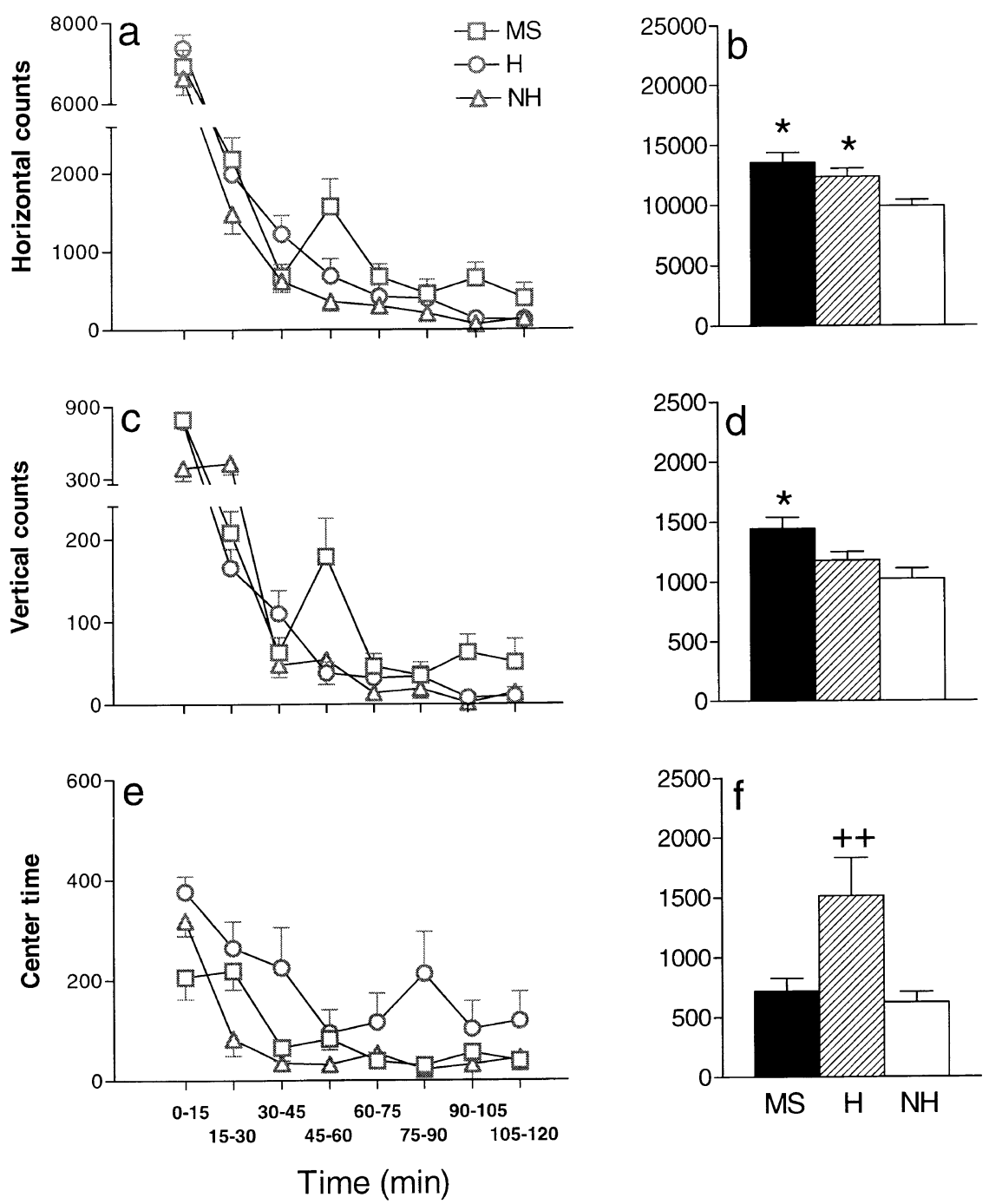

Figure 2. Baseline locomotor activity of maternally-separated (MS), handled $(\mathrm{H})$ and non-handled $(\mathrm{NH})$ animals during the first day of testing. Numbers represent mean $( \pm$ SEM) of horizontal (panels a,b), vertical (panels c,d) activity counts and time (sec) spent in the center of testing arena (panels $\mathrm{e}, \mathrm{f}$ ) in 15-min intervals (panels a, c, e) or as a total $(\mathrm{b}, \mathrm{d}, \mathrm{f}) .{ }^{*} p<.05$ compared with $\mathrm{NH}$ animals; ${ }^{++} p<.05$ compared with other two groups ( $n=16 /$ group). min of testing. In animals receiving saline treatment, initial increase in activity was particularly robust in the $\mathrm{NH}$ group, while declining to low and similar levels thereafter (Figure 3, panels $\mathrm{f}, \mathrm{g}$ ).

Vertical Activity. Activity counts declined over two days of baseline testing in all groups (Figure 4, panels a-c). On day 1 of treatment, activity of animals receiving saline declined even further. Daily injections of 10 $\mathrm{mg} / \mathrm{kg}$ of morphine reduced the vertical activity of MS and $\mathrm{H}$ groups relative to their saline-treated controls (Figure 4, panels a-c). The vertical activity of MS and $\mathrm{H}$ recovered after day 5 and was no longer different from that of corresponding saline-treated animals by day 7 (Figure 4, panels a, b). The pattern of activity changes among $\mathrm{NH}$ animals differed from that of the other animals. Vertical activity, which was uniformly low on day 1 , increased progressively in the group that received saline but remained depressed in the one that received morphine (Figure 4, panel c). Across the morphineexposed groups there was a significant main effect of days $\left(\mathrm{F}_{4,72}=5.28 ; p<.001\right)$, whereas across salineexposed groups there was a significant Days $\times$ Neonatal treatment interaction $\left(\mathrm{F}_{8,84}=5.24 ; p<.0001\right)$.

The time-course analysis on day 1 of treatment revealed that vertical activity of morphine-exposed MS and $\mathrm{H}$ animals was suppressed compared with their saline-treated controls overall throughout the 2-h period (Figure 4, panels d, e). Vertical activity of $\mathrm{NH}$ animals was uniformly low regardless of whether they were treated with morphine or saline (Figure 4, panels d, e). By day 10, activity of morphine-treated MS and $\mathrm{H}$ animals approached the levels of their saline-treated controls, especially during the first 15 min (Figure 4, panel f). As in the case of horizontal activity, initial increase in vertical counts of saline-treated animals was dramatically more robust in $\mathrm{NH}$ than in MS or H groups (Figure 4, panel g).

Center Time. There was no significant change in the center time over two baseline days and when one group began receiving saline injections (Figure 5, panels a, c). 


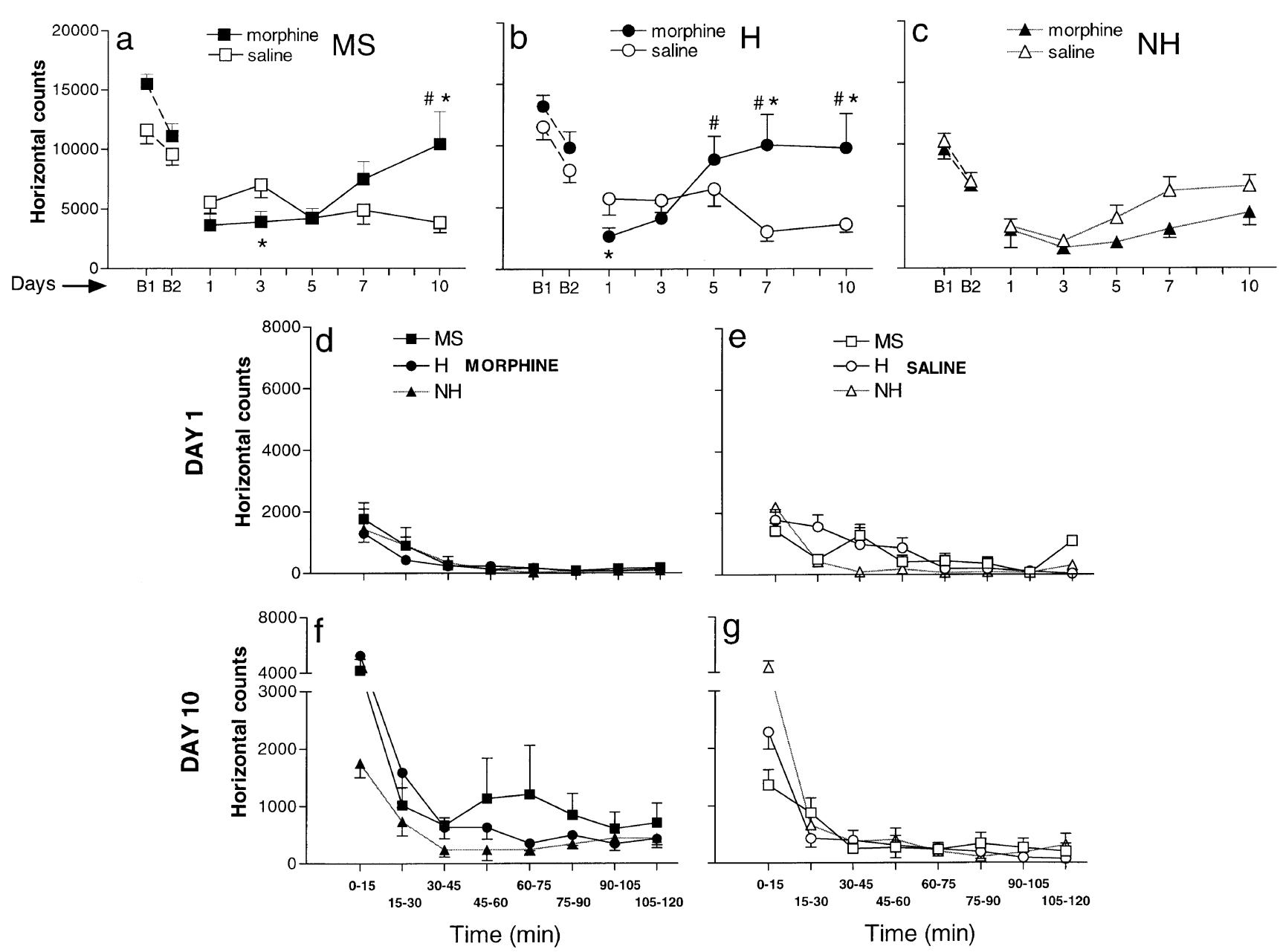

Figure 3. Horizontal activity counts of maternally-separated (MS), handled (H), and non-handled (NH) animals exposed to either saline (open symbols) or $10 \mathrm{mg} / \mathrm{kg}$ of morphine regimens (filled symbols) on two days of baseline activity (B1, B2) and during the induction phase of sensitization. Numbers represent mean ( \pm SEM) total counts (panels a-c) or in 15-min intervals on days 1 and 10 (panels $\mathrm{d}-\mathrm{g}$ ). ${ }^{*} p<.05$ compared with the corresponding saline group; ${ }^{\#} p<.05$ compared with the performance on injection day 1 ( $n=5-8$ /group).

In MS and $\mathrm{H}$ groups, repeated injections of morphine, but not saline, increased time spent in the center of the chamber, beginning on day 3 and, for the most part, persisting throughout the 10 days of treatment (Figure 5 , panels $\mathrm{a}, \mathrm{b}$ ). In the $\mathrm{NH}$ groups, in contrast, time spent in the center did not change throughout the 10 days of treatment (Figure 4, panel c). Across the morphineexposed groups there was a significant main effect of days $\left(\mathrm{F}_{4,72}=3.96 ; p<.01\right)$ and Days $\times$ Neonatal experience interaction approached significance $\left(\mathrm{F}_{8,72}=1.97 ; p=\right.$ .06). There were no significant main effects or significant interactions across the saline-exposed groups.

\section{Expression Phase of Locomotor Tolerance/Sensitization}

Horizontal Activity. In the expression phase, in response to a saline injection, MS was the only group in which animals with the history of morphine exposure had significantly higher $(260 \% ; \mathrm{t}=5.79$; $\mathrm{df}=1 ; 14, p<$ .0001) horizontal counts compared with corresponding saline-history animals (Figure 6, panel a). In general, the two lower doses of morphine increased horizontal activity more in rats with a history of morphine treatment than they did in saline-pretreated rats, regardless of neonatal experience. However, the latter factor contributed to the magnitude of the differences between rats with a history of morphine or saline treatment. For example, $1.0 \mathrm{mg} / \mathrm{kg}$ of morphine resulted in $125 \%$ higher activity counts $(t=6.36$; $d f=1 ; 14, p<.0001)$ by MS animals with a history of morphine treatment than it did by MS animals with a history of saline treatment (Figure 6, panel a). In contrast, $\mathrm{NH}$ animals with a history of morphine exposure had only a $50 \%$ increase in locomotion over saline-history $\mathrm{NH}$ animals $(\mathrm{t}=2.78$; $\mathrm{df}=$ $1 ; 11, p<.05$ ) (Figure 6, panel c), whereas the same measure approached but did not reach statistical significance $(\mathrm{t}=1.89, \mathrm{df}=1 ; 14, p=.08)$ for $\mathrm{H}$ animals (Figure 

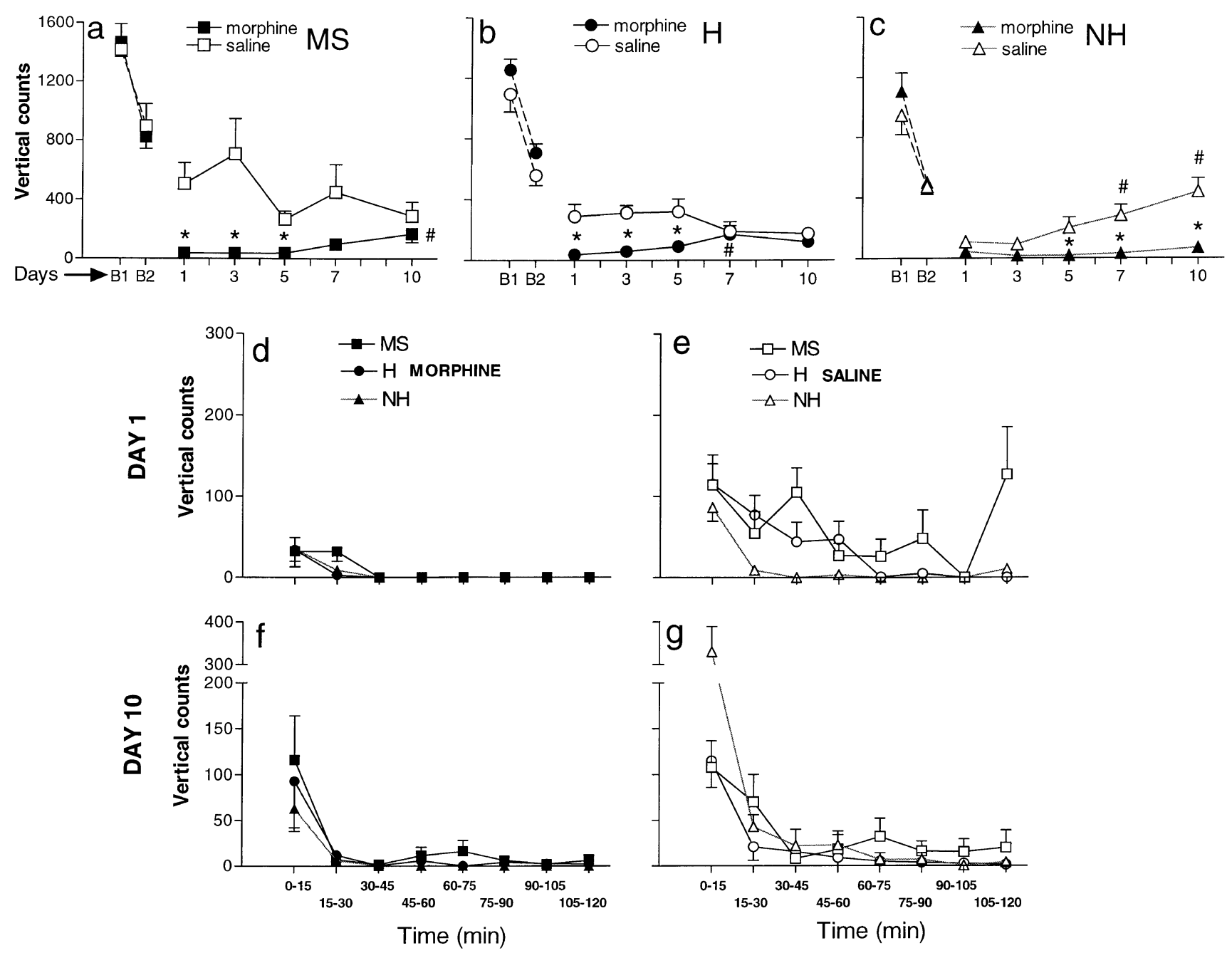

Figure 4. Vertical activity counts of maternally-separated (MS), handled (H), and non-handled (NH) animals exposed to either saline (open symbols) or $10 \mathrm{mg} / \mathrm{kg}$ of morphine regimens (filled symbols) on two days of baseline activity (B1, B2) and during the induction phase of tolerance. Numbers represent mean ( \pm SEM) total counts (panels a-c) or in 15-min intervals on days 1 and 10 (panels d-g). ${ }^{*} p<.05$ compared with the corresponding saline group; ${ }^{\#} p<.05$ compared with the performance on injection day 1 ( $\mathrm{n}=5-8$ /group).

6, panel b). MS, $\mathrm{H}$ and $\mathrm{NH}$ animals were similar in their response to the intermediate and high dose of morphine (Figure 6, panels a-c). For all three groups, 3.0 $\mathrm{mg} / \mathrm{kg}$ of morphine resulted in significant (65-150\%) increases of locomotor activity by animals with a history of morphine exposure over saline-history animals (Figure 6, panels a-c) and $10 \mathrm{mg} / \mathrm{kg}$ of morphine resulted in locomotor activity that was similar in morphine-history and saline-history animals (Figure 6, panels a-c).

Among the groups with a history of morphine treatment, MS animals had significantly higher horizontal counts after a saline injection than did $\mathrm{H}$ and $\mathrm{NH}$ controls $\left(\mathrm{F}_{2,18}=13.28 ; p<.001\right)$ (Figure 6, panel d). In tests with morphine $(1.0-10 \mathrm{mg} / \mathrm{kg})$, there were significant main effects of treatment history (morphine vs. saline) $\left(\mathrm{F}_{1,78}=56.21, p<.0001\right)$, challenge dose $\left(\mathrm{F}_{2,78}=85.34, p<\right.$
$.0001)$, and neonatal experience $\left(\mathrm{F}_{2,78}=5.67 ; p<.01\right)$. Only $1.0 \mathrm{mg} / \mathrm{kg}$ resulted in differences within groups that had the same treatment history: the horizontal activity $\mathrm{H}$ animals was higher than that of the others among groups with a history of saline treatment $\left(\mathrm{F}_{2,21}=\right.$ 7.91; $p<.01$ ) (Figure 6, panel e).

Vertical Counts. In the expression phase, MS and $\mathrm{NH}$ animals with a history of morphine treatment had significantly $(240 \%)$ more vertical counts after an injection of saline than did their counterparts with a history of saline treatment $(\mathrm{t}>2.68 ; \mathrm{df}=1 ; 11-14, p<.05)$ (Figure 7 , panels a, c). In fact, the vertical activity of the former group was higher than that of any other group after the injection of saline $\left(\mathrm{F}_{2,18}=11.94 ; p<.001\right)$ (Figure 7 , panel d). In contrast, the vertical activity of $\mathrm{NH}$ animals with a history of saline treatment was the lowest of any 

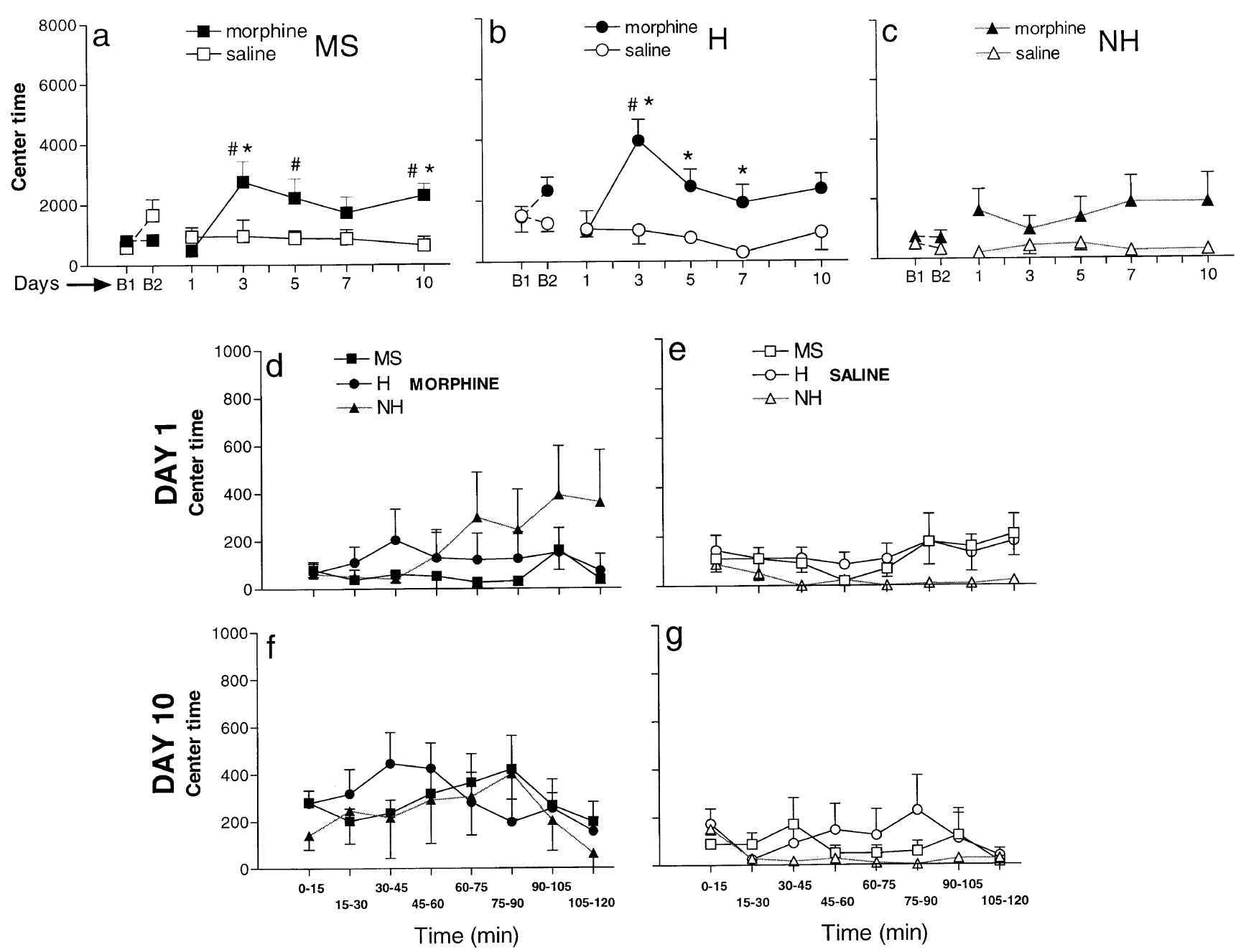

Figure 5. Time (sec) spent in the center of locomotor boxes by maternally-separated (MS), handled (H), and non-handled $(\mathrm{NH})$ animals exposed to either saline (open symbols) or $10 \mathrm{mg} / \mathrm{kg}$ of morphine regimens (filled symbols) on two days of baseline activity (B1, B2) and during the induction phase of sensitization. Numbers represent mean ( \pm SEM) total counts (panels a-c) or in 15-min intervals on days 1 and 10 (panels $\mathrm{d}-\mathrm{g}$ ). ${ }^{*} p<.05$ compared with the corresponding saline group; $\# p<.05$ compared with the performance on injection day 1 ( $\mathrm{n}=5-8$ /group).

group after a saline injection $\left(\mathrm{F}_{2,21}=4.45 ; p<.05\right)$ (Figure 7 , panel e). The two lower doses of morphine tended to increase the vertical activity of rats with a history of morphine treatment more than they increased the activity of rats with a history of saline treatment, effects that were statistically significant at $1.0 \mathrm{mg} / \mathrm{kg}$ in the MS animals $(\mathrm{t}=3.45 ; \mathrm{df}=1 ; 14, p<.01)$ (Figure 7 , panel a) and at $3.0 \mathrm{mg} / \mathrm{kg}$ in the NH animals $(\mathrm{t}=2.76$, $\mathrm{df}=1 ; 11, p<.05$ ) (Figure 7, panel c). In tests with morphine $(1.0-10 \mathrm{mg} / \mathrm{kg})$, there were significant main effects of treatment history $\left(\mathrm{F}_{1,76}=11.59, p<.001\right)$ and challenge dose $\left(\mathrm{F}_{2,76}=62.02, p<.0001\right)$, but not of neonatal experience.

Center Time. In the expression phase, drug history did not influence center time either after saline or after morphine $(1.0-10 \mathrm{mg} / \mathrm{kg}$ ) administration (Figure 8, panels a-c). However, there was an interaction between drug history and neonatal experience: MS and $\mathrm{H}$ animals with the history of morphine treatment spent more time in the center compared with $\mathrm{NH}$ controls $\left(\mathrm{F}_{2,36}=5.78 ; p<.01\right.$; Figure 8 , panel $\left.\mathrm{d}\right)$, whereas animals with a history of saline treatment did not (Figure 8 , panel e).

\section{DISCUSSION}

Repeated maternal separation of Long-Evans male rats during the neonatal period had a powerful and longlasting impact on the animals' motor responses to a novel environment, conditioned locomotor activity, and on induction and expression of morphine-induced sensitization or tolerance to effects of that drug on locomotor ac- 

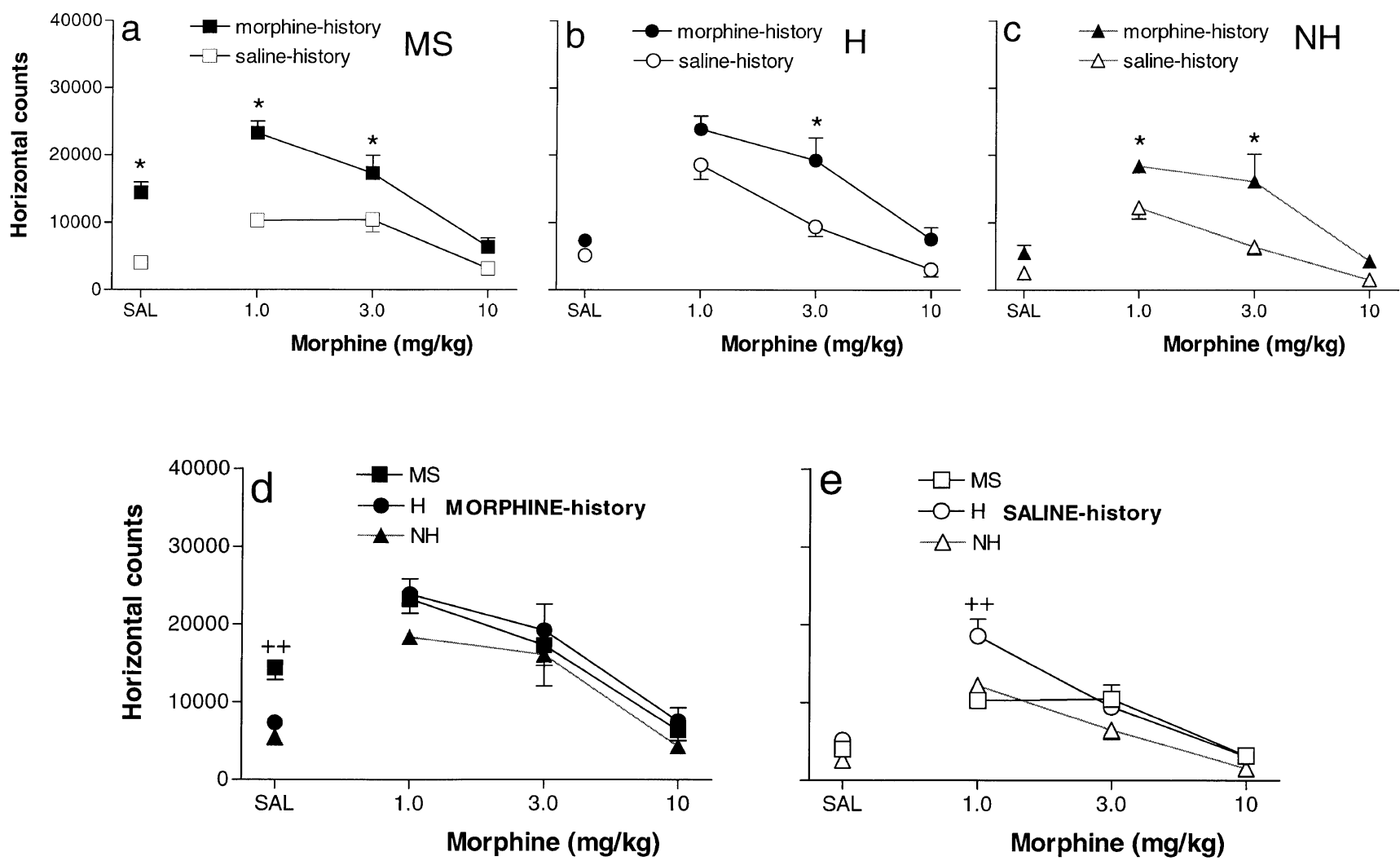

Figure 6. Horizontal activity counts of maternally-separated (MS), handled (H), and non-handled (NH) animals with the history of either saline (open symbols) or $10 \mathrm{mg} / \mathrm{kg}$ of morphine (filled symbols) treatment in response to increasing doses of morphine during the expression phase of sensitization. Each point represents the mean $( \pm \mathrm{SEM})$. ${ }^{*} p<.05$ compared with the corresponding saline group; ${ }^{++} p<.05$ compared with two remaining groups $(\mathrm{n}=5-8 /$ group).

tivity. Rats that experienced daily separations from the mother during the neonatal period (MS and $\mathrm{H}$ ), when tested as adults exhibited elevated locomotor activity in a novel environment. The MS animals exhibited the most robust increases in activity compared with $\mathrm{NH}$ controls, both in horizontal (up to 50\%) and vertical (up to $75 \%$ ) activity counts. The increase in activity by the $\mathrm{H}$ group was more modest (up to $30 \%$ ) and occurred only in horizontal counts. Elevated horizontal activity in animals with maternal separation or handling experience over non-handled controls also has been reported for Wistar rats (Pryce et al. 2001).

On the first day of testing, whereas MS animals explored the arena primarily near walls, $\mathrm{H}$ animals spent significantly more time exploring the center of the test chamber compared with MS and NH animals. The decreased tendency of $\mathrm{H}$ animals to stay near the walls may be related to a reduction in emotional reactivity as a result of neonatal handling (Denenberg 1964; Levine et al. 1967; Caldji et al. 2000). With daily injections of saline (saline group), the difference in horizontal and vertical activity and time in the center among MS, $\mathrm{H}$ and $\mathrm{NH}$ animals gradually disappeared. On day 10 of testing MS and $\mathrm{H}$ animals had even somewhat lower horizontal counts compared with $\mathrm{NH}$ controls.
Similar to the effects of maternal separation on locomotor responsiveness to novelty, prenatal stress or prolonged social isolation in the rat is associated with enduring locomotor hyperactivity (Sahakian et al. 1975; Garzon and Del Rio 1981; Ehlers et al. 1989; Henry et al. 1994). This effect is likely due to hyperactivity of the mesolimbic dopaminergic system (Geyer et al. 1993) or altered dopamine sensitivity in the nucleus accumbens (Henry et al. 1995). Forebrain dopamine depletion attenuates locomotor activity in a novel environment and blocks novelty-induced place preference (Pierce et al. 1990; Robbins and Everitt 1995). Therefore, locomotor hyperactivity of MS animals in a novel environment might be indicative of a hyperactive mesolimbic dopamine system. In support of this possibility, 10-day-old pups that experienced repeated 1-h separation from the mother on PND 2-9 had increased dopamine turnover in several target areas of the mesolimbic system, such as septum and hypothalamus; moreover, amphetamineinduced dopamine release in the nucleus accumbens was potentiated (Kehoe et al. 1998b). Some of these changes in sensitivity to amphetamine and in dopamine system activity as a result of maternal separation could be long lasting and possibly permanent (Pryce et al. 2001). 

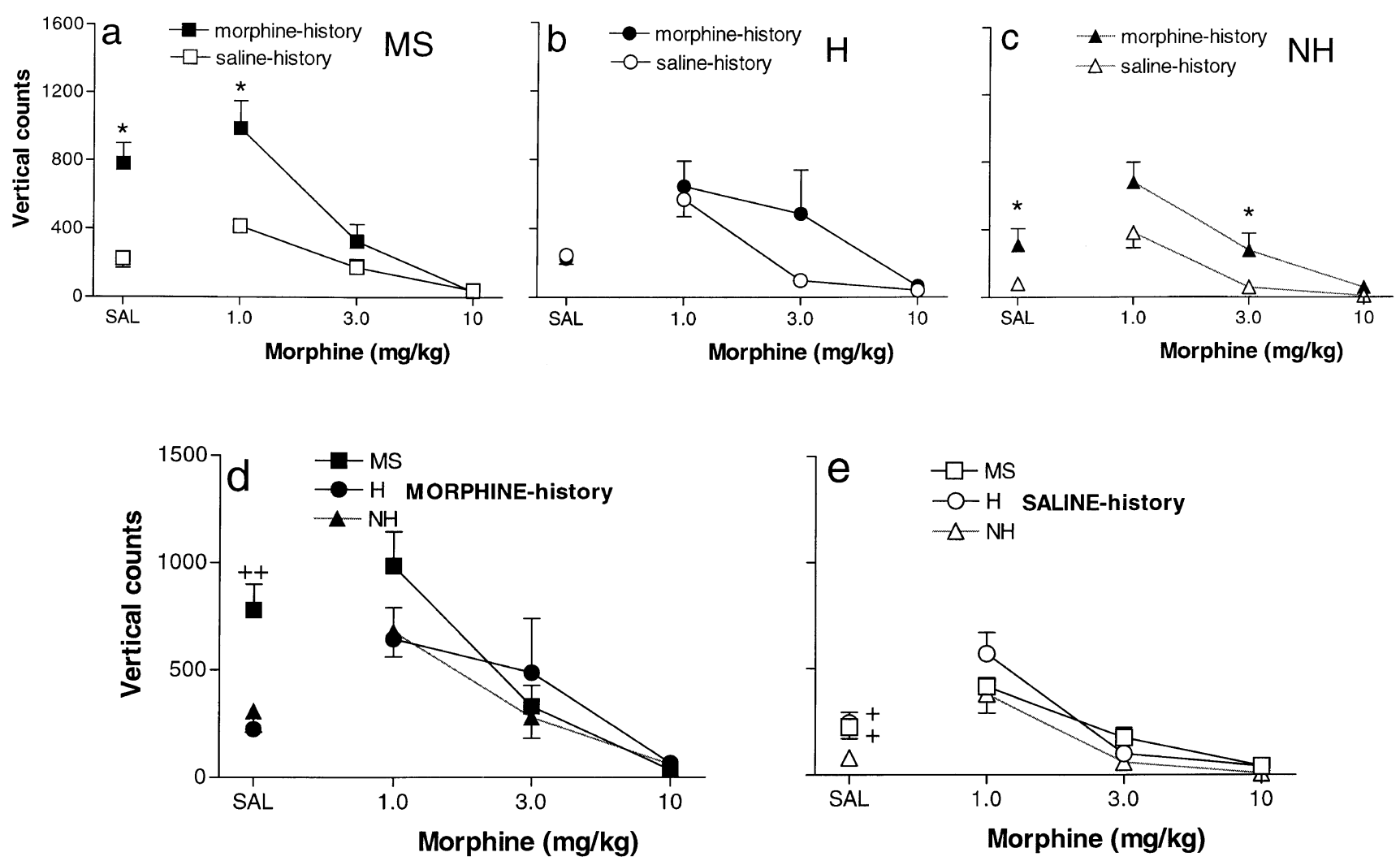

Figure 7. Vertical activity counts of maternally-separated (MS), handled (H), and non-handled (NH) animals with history of either saline (open symbols) or $10 \mathrm{mg} / \mathrm{kg}$ of morphine (filled symbols) treatment in response to increasing doses of morphine during the expression phase of sensitization. Each point represents the mean $( \pm \mathrm{SEM}){ }^{*} p<.05$ compared with corresponding saline group; ${ }^{++} p<.05$ compared with two remaining groups; ${ }^{+} p<.05$ compared with the NH group (n $=5-8$ ).

There is growing evidence that in the rat locomotor reactivity to a novel environment positively correlates with novelty-induced corticosterone release (Piazza and Le Moal 1991), sensitivity to locomotor stimulant effects of amphetamine (Piazza et al. 1989), and amphetamineinduced sensitization (Hooks et al. 1991). Furthermore, rats that exhibit high levels of locomotion in a novel environment (high responders) are more likely to acquire amphetamine self-administration, and to administer higher quantities of the drug and are more sensitive to rewarding effects of amphetamine compared with animals with low levels of locomotion in a novel environment (low responders; Pierre and Vezina 1997; Klebaur and Bardo 1999). Some of the phenotypic differences between MS and $\mathrm{NH}$ animals resemble those between high and low responders. In particular, MS animals, similar to high responders, exhibit elevated locomotor responses to novel environment and secrete higher levels of corticosterone in response to either novelty or mild handling compared with $\mathrm{H}$ and $\mathrm{NH}$ animals (Biagini et al. 1998; Kalinichev et al. 2002). Based on related findings (Kehoe et al. 1998a; Matthews et al. 1999, Huot et al. 2001) it can be predicted that maternally-separated animals will be more likely to self-administer amphetamine than will non-separated controls. An association among locomotor reactivity to novelty, stress-induced HPA activation, and sensitivity to psychomotor stimulant/opioid drugs also is suggested by the results of studies that involve other types of environmental manipulation, such as prolonged social isolation and prenatal stress (Deminiere et al. 1992; Bowling and Bardo 1994; Henry et al. 1994; Henry et al. 1995; Bardo et al. 1997).

MS and $\mathrm{H}$ males differed from NH controls in both the induction and expression phases of altered locomotor responses to morphine, especially in the induction phase. In this phase, the locomotor activity of MS and $\mathrm{H}$ animals, suppressed initially by $10 \mathrm{mg} / \mathrm{kg}$ of morphine, rapidly reached levels of the corresponding salinetreated groups, indicative of tolerance. Horizontal activity continued to increase relative to corresponding saline-treated animals, indicative of behavioral sensitization. Induction of tolerance in MS and $\mathrm{H}$ animals by repeated morphine injections was even more pronounced for vertical activity (i.e., rearing behavior). In sharp contrast to MS and $\mathrm{H}$ animals, $\mathrm{NH}$ controls failed to exhibit either behavioral sensitization (horizontal activity) or tolerance (vertical activity) during the first 10 days of testing.

The difference between the animals that experienced periodic separations from the dam (MS and $\mathrm{H}$ groups) 

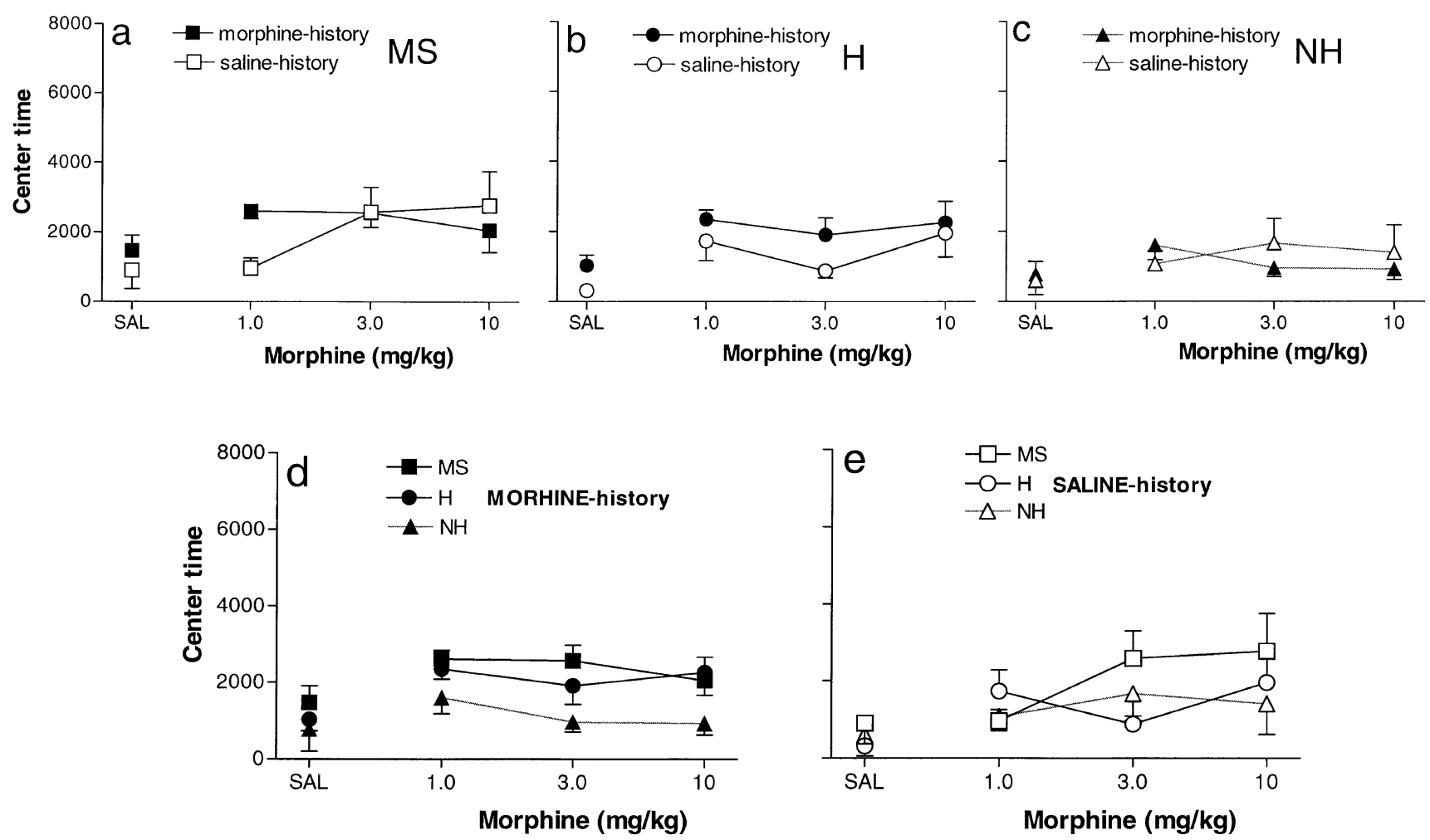

Figure 8. Time (sec) spent in the center of locomotor boxes by maternally-separated (MS), handled (H), and non-handled $(\mathrm{NH})$ animals with history of either saline (open symbols) or $10 \mathrm{mg} / \mathrm{kg}$ of morphine (filled symbols) treatment in response to increasing doses of morphine during the expression phase of sensitization. Each point represents the mean $( \pm$ SEM; $\mathrm{n}=$ 5-8/group).

or were undisturbed as neonates (NH group) was evident also in responsiveness to daily injections of saline. In particular, the regimen of saline injections increased vertical and horizontal (as a trend) counts in $\mathrm{NH}$, but not in MS and $\mathrm{H}$ animals. Time course analysis revealed that by day 10 activity immediately after the saline injection was considerably higher in $\mathrm{NH}$ animals compared with the MS and $\mathrm{H}$ groups. Exposure to daily morphine appeared to block the development of this hyperactivity. Perhaps, some form of sensitization as the results of daily injections does occur in $\mathrm{NH}$ animals (Wilcox et al. 1986). There is some evidence that experience of being completely undisturbed during the first few weeks of life (as in the NH group) yields a phenotype that differs markedly from that of animals that received typical animal husbandry (Pryce et al. 2001). Perhaps, the post-saline-injection increase in activity of $\mathrm{NH}$ animals is associated with altered reactivity to stress, as indicated by some authors (Caldji et al. 2000; Pryce et al. 2001). However, the potentiation of activity was brief and did not influence the activity in the center of the locomotor arena.

In the expression phase, MS rats was the only group in which animals with the history of morphine treatment had increases in horizontal and vertical activity after an injection of saline. Those increases in locomotor activity of MS animals were remarkably robust (240 $260 \%$ ) despite the fact that some of the morphine injections were given in the home cage, a design that usually minimizes conditioning. Moreover, both horizontal and vertical activities increased after saline administration even though previous daily injections of morphine had increased only horizontal activity. In contrast to the activity level of MS animals after a saline injection, the activity of $\mathrm{H}$ animals did not increase and only the vertical activity of $\mathrm{NH}$ animals was higher than that of the corresponding group treated previously with saline. The elevated activity of MS animals after a saline injection probably is unrelated to the neuroadaptations that occur during the development of sensitization or tolerance. $\mathrm{H}$ animals had a more rapid onset of sensitization (horizontal counts) than did MS animals and had a similar rate of tolerance development (vertical counts) but exhibited no increases in activity after a saline injection on day 15.

The elevated activity of MS animals after a saline injection could be related to the exaggerated reactivity to stress exhibited by these animals (Plotsky and Meaney 1993; Huot et al. 2001; Kalinichev et al. 2002). According to Wilcox et al. (1986), stress of repeated injections by it- 
self can result in an enduring enhancement of amphetamine-stimulated striatal dopamine release. Even though there was no enhancement of activity in MS animals following daily saline treatment, perhaps stress of daily injections in addition to the daily morphine regimen resulted in the greater sensitization of this group. In accord with this hypothesis restraint stress potentiated morphine-induced antinociception in Long-Evans male rats that experience maternal separation as neonates (Easterling et al. 1999). Such potentiation was absent in $\mathrm{H}$ and $\mathrm{NH}$ males, supporting previous findings from our laboratory (Woolfolk and Holtzman 1995).

There are alternative possibilities to explain an increase in context-specific motor activity on a non-drug test day in MS animals. Increases in horizontal and vertical activity after an injection of saline can be attributed to associative learning (i.e., Pavlovian conditioning). The phenomenon of increased activity, conditioned to the presentation of specific environmental cues has been described also for the administration of amphetamine and cocaine (Beninger and Hahn 1983; Burechailo and Martin-Iverson 1996; Anagnostaras and Robinson 1996). Robust conditioning of MS animals compared with other groups may be indicative of powerful and long-lasting alterations in general learning and attention processes as the result of maternal separation. In support to this hypothesis, repeated, 1-h separation from the mother on PND 2-9 led to an increased magnitude and prolonged duration of long-term potentiation (LTP) in juvenile rats, an effect that could be long-lasting (Kehoe et al. 1995; Bronzino et al. 1996). Furthermore, latent inhibition, a direct measure of learning/attention processes in the rat, was increased in adult offspring that experienced repeated 6-h separation on PND 12-18 in all learning paradigms applied: two-way active avoidance, conditioned emotional response, and conditioned taste aversion (Lehmann et al. 1998, 2000).

According to the frustrative non-reward hypothesis (Amsel 1958, 1962; Martin-Iverson and Fawcett 1996), developed anticipation of a reward-like state as a result of daily drug exposure can change into a frustrative non-reward-like state, causing increased locomotion on a non-drug day. While being prone to elevated fear and anxiety (Wigger and Neumann 1999; Huot et al. 2001; Kalinichev et al. 2002), MS animals also might develop exaggerated responses to frustrative non-reward. On the other hand, MS animals might be more reactive to the disconfirmation of expected environmental contextdrug association that occurs on a non-drug day and increase exploration (Martin-Iverson and Fawcett 1996). Exploratory behavior of MS animals on the first day of testing in the novel chambers was the highest of the three groups.

In the expression phase, when animals with and without a history of daily morphine treatment were challenged with a range of morphine doses, additional differences between the MS and NH groups, although less dramatic, emerged at the two lower doses. The apparent conditioning of motor stimulation in MS animals makes it difficult to interpret the increases in sensitivity to morphine ( 1.0 and $3.0 \mathrm{mg} / \mathrm{kg}$ ) of the morphine-experienced rats relative to the corresponding saline-experienced groups. That increased sensitivity could represent either sensitization to locomotor stimulant effects of morphine or the combined effect of conditioning and exposure to the drug. However, this is not a problem when it comes to the horizontal activity of morphineexperienced $\mathrm{H}$ and $\mathrm{NH}$ animals. These groups did not exhibit a conditioned increase in activity after a saline injection but had higher activity than that of the corresponding saline-experienced groups after receiving 1.0 or $3.0 \mathrm{mg} / \mathrm{kg}$ morphine. The fact that morphine-induced locomotor sensitization of the MS and NH groups was similar in the expression phases despite the lack of sensitization of the $\mathrm{NH}$ group during the induction phase, further supports the hypothesis that these two phases of behavioral sensitization are mediated by distinct mechanisms (Cador et al. 1995).

In some of the measures of spontaneous locomotor activity and morphine-induced sensitization and tolerance, $\mathrm{H}$ animals resembled MS animals, while in others, they were similar to $\mathrm{NH}$ animals. A similar pattern has been observed by other investigators. While being significantly different from $\mathrm{NH}$ animals, $\mathrm{H}$ and MS animals had similar levels of spontaneous locomotor activity (Pryce et al. 2001) and locomotor activity following restraint stress (Kehoe et al. 1998a). However, amphetamine resulted in a similar level of activity in $\mathrm{H}$ and $\mathrm{NH}$ animals, which was significantly lower than that activity exhibited by MS animals (Kehoe et al. 1998a; Pryce et al. 2001).

Behavioral sensitization and tolerance induced by morphine and related opioids are mediated by $\mu$ - and, possibly, $\delta$-opioid receptors, although the precise mechanisms that account for these phenomena remain obscure. The differences in sensitization/tolerance among the MS, $\mathrm{H}$ and $\mathrm{NH}$ groups might reflect differences in neuroadaptive changes in opioid receptor numbers and/or coupling with the second messenger systems. Preliminary findings from several laboratories indicate that repeated maternal separation of rat pups results in long-lasting changes in $\mu$ - and $\kappa$-opioid receptor density as well as dynorphin mRNA levels in several areas of the brain (Ploj et al. 1999; Yuferov et al. 2000). Group differences in the induction of sensitization and tolerance were large whereas group differences in the expression phase were modest. Therefore, it is likely that MS, $\mathrm{H}$ and $\mathrm{NH}$ groups differ in time courses rather than in actual mechanisms of sensitization and tolerance. On the other hand, the differences among, MS, $\mathrm{H}$ and $\mathrm{NH}$ animals in behavioral sensitization and tolerance could reflect differences in stress-reactivity in relation to the 
injections and testing. There is some evidence that repeated exposure to various stressors, such as foot-shock or restraint, augment sensitivity to behavioral activating effects of opioids (Leyton and Stewart 1990; Deroche et al. 1992; Shaham et al. 1995). However, such interpretation is unlikely because $\mathrm{H}$ animals, which are characterized by hyporesponsiveness to stress (Plotsky and Meaney 1993), exhibited a more rapid onset of behavioral sensitization than did MS animals.

Our findings also suggest that MS, $\mathrm{H}$, and $\mathrm{NH}$ animals differ in locomotor sensitivity to acute morphine. In the induction phase, initial injections of $10 \mathrm{mg} / \mathrm{kg}$ of morphine significantly reduced the horizontal activity of MS and $\mathrm{H}$ animals below levels of their saline-treated counterparts but did not decrease the horizontal activity of $\mathrm{NH}$ animals. In the expression phase, $1.0 \mathrm{mg} / \mathrm{kg}$ of morphine produced significantly more horizontal activity in $\mathrm{H}$ animals with a history of saline treatment than it did in MS and NH animals. Thus, under some circumstances, $\mathrm{NH}$ animals were less sensitive to the locomotor-suppressant effect of morphine than were the other groups whereas $\mathrm{H}$ animals were more sensitive to the locomotor-stimulant effect of the drug. The results of this study support and expand our previous findings (Kalinichev et al. 2001a,b) that repeated separation of Long-Evans rat pups from the mother results in longlasting changes in sensitivity to effects of morphine, both acute and chronic. Moreover, they are consistent with our hypothesis that these enduring changes in sensitivity to morphine reflect significant alterations in endogenous opioid systems.

\section{ACKNOWLEDGMENTS}

This study was supported by NIH grant DA11384 and Senior Scientist Award K05 DA00008 to S.G.H. We thank Paul M. Plotsky, Ph.D., for his valuable advice on the protocol for the early maternal separation procedure.

\section{REFERENCES}

Amsel A (1958): The role of frustrative nonreward in noncontinuous reward situations. Psychol Bull 55:102-119

Amsel A (1962): Frustrative nonreward in partial reinforcement and discrimination learning: some recent history and theoretical extension. Psychol Bull 69:309-328

Amsterdam JD, Maislin G, Winokur A, Kling M, Gold P (1987): Pituitary and adrenocortical responses to the ovine corticotropin-releasing hormone in depressed patients and healthy volunteers. Arch Gen Psychiatr 44:775-781

Anagnostaras SG, Robinson TE (1996): Sensitization to the psychomotor stimulant effects of amphetamine: modulation by associative learning. Behav Neurosci 110: 1397-1414
Arellano CM (1996): Child maltreatment and substance use: a review of the literature. Subst Use Misuse 31:927-935

Babbini M, Davis WM (1972): Time-dose relationship for locomotor activity effects of morphine after acute or repeated treatment. Br J Pharmacol 46:213-224

Babbini M, Gaiardi M, Bartoletti A (1975): Persistence of chronic morphine effects upon activity in rats 8 months after ceasing the treatment. Neuropharmacology 14: 611-614

Bardo MT, Robinet PM, Hammer RF Jr (1997): Effect of differential rearing environments on morphine-induced behaviors, opioid receptors and dopamine synthesis. Neuropharmacology 36:251-259

Barr GA (1993): Reinforcing properties of opiates during early development. In Hammer RP Jr (ed), The Neurobiology of Opiates. Boca Raton, FL, CRC Press, pp 63-83

Bartoletti M, Gaiardi M, Gubellini G, Bacchi A, Babbini M (1983): Long-term sensitization to the excitatory effects of morphine. Neuropharmacology 22:1193-1196

Bayon A, Shoemaker WJ, Bloom FE, Mauss A, Guillemin R (1979): Perinatal development of the endorphine- and enkephalin-containing systems in the rat brain. Brain Res 179:93-101

Beninger RJ, Hahn BL (1983): Pimozide blocks establishment but not expression of amphetamine-produced environment-specific conditioning. Science 220:1304-1306

Bernet CZ, Stein MB (1999): Relationship of childhood maltreatment to the onset and course of major depression in adulthood. Depress Anxiety 9:169-174

Berridge KC, Robinson TE (1995): The mind of an addicted brain: Neural sensitization of wanting versus liking. Current Directions in Psychological Science 4:71-76

Biagini G, Pich EM, Carani C, Marrama P, Agnati LF (1998): Postnatal maternal separation during the stress hyporesponsive period enhances the adrenocortical response to novelty in adult rats by affecting feedback regulation in the CA1 hippocampal field. Int J Devl Neuroscience 16:187-197

Bowling SL, Bardo MT (1994): The locomotor and rewarding effects of amphetamine in enriched, social, and isolate reared rats. Pharmacol Biochem Behav 48:459-464

Brady LS, Holtzman SG (1981): Locomotor activity in morphine-dependent and post-dependent rats. Pharmacol Biochem Behav 14:361-370

Bronzino JD, Kehoe P, Austin-LaFrance RJ, Rushmore RJ, Kurdian J (1996): Neonatal isolation alters LTP in freely moving juvenile rats: sex differences. Brain Res Bull 41:175-183

Burechailo L, Martin-Iverson MT (1996): Behavioral sensitization to cocaine, but not cocaine-conditioned behavior, is associated with increased dopamine occupation of its receptors in the nucleus accumbens. Behav Neurosci 110:1388-1396

Cador M, Bjijou Y, Stinus L (1995): Evidence of a complete independence of the neurobiological substrates for the induction and expression of behavioral sensitization to amphetamine. Neuroscience 65:385-395

Caldji C, Francis D, Sharma S, Plotsky PM, Meaney MJ (2000): The effects of early rearing environment on the 
development of $\mathrm{GABA}_{\mathrm{A}}$ and central benzodiazepine receptor levels and novelty-induced fearfulness in the rat. Neuropsychopharmacology 22:219-229

Campbell J, Spear LP (1999): Effects of early handling on amphetamine-induced locomotor activation and conditioned place preference in the adult rat. Psychopharmacology (Berl) 143:183-189

Deminiere JM, Piazza PM, Guegan G, Abrous N, Maccari S, Le Moal M, Simon H (1992): Increased locomotor response to novelty and propensity to intravenous amphetamine self-administration in adult offspring of stressed mothers. Brain Res 586:135-139

Denenberg VH (1964): Critical periods, stimulus input, and emotional reactivity: a theory of infantile stimulation. Psychol Rev 71:335-351

Deroche V, Piazza PM, Casolini P, Maccari S, Le Moal M, Simon H (1992): Stress-induced sensitization to amphetamine and morphine psychomotor effects depend on stress-induced corticosterone secretion. Brain Res 598:343-348

Duncan RD, Saunders BE, Kilpatrick DG, Hanson RF, Resnick HS (1996): Childhood physical assault as a risk factor for PTSD, depression, and substance abuse: findings from a national survey. Am J Orthopsychiatry 66:437-448

Easterling KW, Kalinichev M, Holtzman SG (1999): Neonatal maternal separation produces a profile of altered corticosterone levels and sensitivity to morphine. Society for Neuroscience Abstracts 25:1324

Ehlers CL, Wall TL, Wyss SP, Chaplin RI (1989): Social zeitgebers: a peer separation model of depression in rats. In Koob GF, Ehlers CL, Kupfer DJ (eds), Animal Models of Depression. Boston, Birkhauser, pp 99-110

Garzon J, Del Rio J (1981): Hyperactivity induced in rats by long-term isolation: further studies on a new animal model for the detection of antidepressants. Eur J Pharmacol 74:278-294

Geyer MA, Wilkinson LS, Humby T, Robbins TW (1993): Isolation rearing of rats produces a deficit in prepulse inhibition of acoustic startle similar to that in schizophrenia. Biol Psychiatry 34:361-372

Harro J (1993): Measurement of exploratory behavior in rodents. In Conn PM (ed) Paradigms for the measurement of behavior. San Diego, Academic Press, pp 359-377

Hauser KF, Stiene-Martin A (1993): Opiates and the regulation of nervous system development: evidence from in vitro studies. In Hammer RP Jr (ed), The Neurobiology of Opiates. Boca Raton, FL, CRC Press, pp 23-61

Heim C, Owens MJ, Plotsky PM, Nemeroff CB (1997): Persistent changes in corticotropin-releasing factor system due to early life stress: Relationship to the pathophysiology of major depression and post-traumatic stress disorder. Psychopharmacol Bull 33:185-192

Heim C, Newport DJ, Heit S, Graham YP, Wilcox M, Bonsall R, Miller AH, Nemeroff CB (2000): Pituitary-adrenal and autonomic responses to stress in women after sexual and physical abuse in childhood. JAMA 284:592-597

Heit S, Owens MJ, Plotsky PM, Nemeroff CB (1997): Corticotropin-releasing factor, stress, and depression. The Neuroscientists 3:186-194
Henry C, Kabbaj M, Simon H, Le Moal M, Maccari S (1994): Prenatal stress increases the hypothalamo-pituitaryadrenal axis response in young and adult rats. J Neuroendocrinol 6:341-345

Henry C, Guegant G, Cador M, Arnauld E, Arsault J, Le Moal M, Demotes-Mainard J (1995): Prenatal stress in rats facilitates amphetamine-induced sensitization and induces long-lasting changes in dopamine receptors in the nucleus accumbens. Brain Res 685:179-186

Hooks MS, Jones GH, Smith AD, Neill DB, Justice JB (1991): Individual differences in locomotor activity and sensitization. Pharmacol Biochem Behav 38:467-470

Huot RL, Thrivikraman KV, Meaney MJ, Plotsky PM (2001): Development of adult ethanol preference and anxiety as a consequence of neonatal maternal separation in Long Evans rats and reversal with antidepressant treatment. Psychopharmacology (Berl) 158:366-373

Ireland T, Widom CS (1994): Childhood victimization and risk for alcohol and drug arrests. International Journal of Addiction 29:235-274

Ivinskis A (1970): A study of validity of open-field measures. Australian J Psychol 22:175-183

Kalinichev M, Easterling KW, Holtzman SG (2000): Periodic postpartum separation from the offspring results in long-lasting changes in anxiety-related behaviors and sensitivity to morphine in Long-Evans mother rats. Psychopharmacology (Berl) 152:431-439

Kalinichev M, Easterling KW, Holtzman SG (2001a): Repeated neonatal maternal separation alters morphine-induced antinociception in male rats. Brain Res Bull 54:649-654

Kalinichev M, Easterling KW, Holtzman SG (2001b): Early neonatal experience of Long-Evans rats results in longlasting changes in morphine tolerance and dependence. Psychopharmacology (Berl) 157:305-312

Kalinichev M, Easterling KW, Plotsky PM, Holtzman SG (2002): Long-lasting changes in stress-induced corticosterone response and anxiety-like behaviors as a consequence of neonatal maternal separation in Long-Evans rats. Pharmacol Biochem Behav (In press)

Kalivas PW, Stewart J (1991): Dopamine transmission in the initiation and expression of drug- and stress-induced sensitization of motor activity. Brain Res Rev 16:223-244

Kehoe P, Hoffman JH, Austin-LaFrance RJ, Bronzino JD (1995): Neonatal isolation enhances hippocampal dentate response to tetanization in freely moving juvenile male rats. Exp Neurol 136:89-97

Kehoe P, Shoemaker WL, Triano L, Callahan M, Rapport G (1998a): Adult rats stressed as neonates show exaggerated behavioral responses to both pharmacological and environmental challenges. Behav Neurosci 112:116-125

Kehoe P, Shoemaker WL, Arons C, Triano L, Suresh G (1998b): Repeated isolation stress in the neonatal rat: relation to brain dopamine systems in the 10-day-old rat. Behav Neurosci 112:1466-1474

Klebaur JE, Bardo MT (1999): Individual differences in novelty seeking on the playground maze predict amphetamine conditioned place preference. Pharmacol Biochem Behav 63:131-136

Kosten TA, Miserendino MJD, Kehoe P (2000): Enhanced acquisition of cocaine self-administration in adult rats 
with neonatal isolation stress experience. Brain Res 875:44-50

Ladd CO, Huot RL, Thrivikraman KV, Nemeroff CB, Meaney MJ, Plotsky PM (2000): Long-term behavioral and neuroendocrine adaptations to adverse early experience. In Mayer EA, Saper CB (eds), Progress in Brain Research: The Biological Basis for Mind Body Interactions. Amsterdam, Elsevier Science, pp 81-103

Lehmann J, Stöhr T, Schuller J, Domeney A, Heidbreder C, Feldon J (1998): Long-term effects of repeated maternal separation on three different latent inhibition paradigms. Pharmacol Biochem Behav 59:873-882

Lehmann J, Stöhr T, Feldon J (2000): Long-term effect of prenatal stress experience and postnatal maternal separation on emotionality and attentional processes. Behav Brain Res 107:133-144

Levine S, Haltmeyer GC, Karas GG, Denenberg VH (1967): Psychological and behavioral effects of infantile stimulation. Physiol Behav 2:55-59

Leyton M, Stewart J (1990): Preexposure to foot-shock sensitizes the locomotor response to subsequent systemic morphine and intranucleus accumbens amphetamine. Pharmacol Biochem Behav 37:303-310

Liu D, Caldji C, Sharma S, Plotsky PM, Meaney MJ (2000): Influence of neonatal rearing conditions on stressinduced adrenocorticotropin responses and norepinephrine release in the hypothalamic paraventricular nucleus. J Neuroendocrinol 12:5-12

Martin-Iverson MT, Fawcett SL (1996): Pavlovian conditioning of psychomotor stimulant-induced behaviors: Has convenience led us astray? Behav Pharmacol 7:24-41

Matthews K, Wilkinson LS, Robbins TW (1996): Retarded acquisition and reduced expression of conditioned locomotor activity in adults rats following repeated early maternal separation: effects of prefeeding, $d$-amphetamine, dopamine antagonists and clonidine. Psychopharmacology (Berl) 126:75-84

Matthews K, Robbins TW, Everitt BJ, Caine SB (1999): Repeated neonatal maternal separation alters intravenous cocaine self-administration in adult rats. Psychopharmacology (Berl) 141:123-134

Medrano MA, Zule WA, Hatch J, Desmond DP (1999): Prevalence of childhood trauma in a community sample of substance-abusing women. Am J Drug Alcohol Abuse 25:449-462

Petitto JM, Quade D, Evans DL (1992): Relationship of object loss during development to hypothalamo-pituitaryadrenal axis function during major affective illness later in life. Psychol Res 44:227-236

Petrillo P, Tavani A, Verotta D, Robons LE, Kosterlitz HW (1987): Differential postnatal development of $\mu-, \delta$ - and к-opioid binding sites in rat brain. Dev Brain Res 31:53-58

Piazza PM, Deminiere JM, Le Moal M, Simon H (1989): Factors that predict individual vulnerability to amphetamine self-administration. Science 245:1511-1513

Piazza PM, Le Moal M (1991): Corticosterone levels determine individual vulnerability to amphetamine selfadministration. Processes of National Academy of Sciences USA 88:2088-2092

Pierce RC, Crawford CA, Nonneman AJ, Mattingly BA, Bardo MT (1990): Effect of forebrain dopamine deple- tion on novelty-induced place preference behavior in rats. Pharmacol Biochem Behav 36:321-325

Pierre PJ, Vezina P (1997): Predisposition to self-administer amphetamine: the contribution of response to novelty and prior exposure to the drug. Psychopharmacology (Berl) 129:277-284

Ploj K, Pharm TM, Bergström L, Mohammed AH, Henriksson BG, Nylander I (1999): Neonatal handling in rats induces long-term effects on dynorphin peptides. Neuropeptides 33:468-474

Plotsky PM, Meaney MJ (1993): Early postnatal experience alters hypothalamic corticotropin-releasing factor (CRF) mRNA, median eminence CRF content and stress induced release in adult rats. Molec Brain Res 18:195-200

Powell KR, Holtzman SG (2001): Parametric evaluation of the development of sensitization to the effects of morphine on locomotor activity. Drug Alcohol Depend 62:83-90

Pryce CR, Bettschen D, Bahr NI, Feldon J (2001): Comparison of the effects of infant handling, isolation, and nonhandling on acoustic startle, prepulse inhibition, locomotion and HPA activity in the adult rat. Behav Neurosci 115:71-83

Rauhala P, Idänpään-Heikkilä JJ, Tuominen RK, Männistö PT (1995): Differential disappearance of tolerance to thermal, hormonal and locomotor effects of morphine in the male rat. Eur J Pharmacol 285:69-77

Robbins TW, Everitt BJ (1995): Arousal systems and attention. In Gazzaniga $M$ (ed), The Cognitive Neurosciences. Cambridge, MA, MIT Press, pp 703-720

Robinson TE, Berridge KC (1993): The neural basis of drug craving: an incentive salience theory of addiction. Brain Research Reviews 18:247-291

Sahakian BJ, Robbins TW, Morgan MJ, Iversen SD (1975): The effects of psychomotor stimulants on stereotypy and locomotor activity in socially-deprived and control rats. Brain Res 84:195-205

Servant D, Parquet PJ (1994): Early life events and panic disorder: Course of illness and comorbidity. Prog Neuropsychopharmacol Biol Psychiatry 18:373-379

Shaham Y, Kelsey JE, Stewart J (1995): Temporal factors in the effect of restraint stress on morphine-induced behavioral sensitization in the rat. Psychopharmacology (Berl) 117:102-109

Spain JW, Roth BL, Coscia CJ (1985): Differential ontogeny of multiple opioid receptors $(\mu, \delta$ and $\kappa)$. J Neurosci 5:584-588

Spanagel R, Almeida OFX, Shippenberg TS (1993): Long lasting changes in morphine-induced mesolimbic dopamine release after chronic morphine exposure. Synapse 14:243-245

Stewart J, Badiani A (1993): Tolerance and sensitization to the behavioral effects of drugs. Behav Pharmacol 4:289-312

Tsang D, Ng NC, Ho KP, Ho WKK (1982): Ontogenesis of opiate binding sites and radioimmunoassayable endorphin and enkephalin in regions of rat brain. Dev Brain Res 5:257-261

Triffleman EG, Marmar CR, Delucchi KL, Ronfeldt H (1995): Childhood trauma and posttraumatic stress disorder in substance abuse inpatients. J Nerv Ment Dis 183:172-176 
Valle FP (1970): Effects of strain, sex, and illumination on open-field behavior of rats. Am J Psychol 83:103-111

Walsh RN, Cummins RA (1976): The open-field test: A critical review. Psychol Bull 83:482-504

Widom CS (1999): Posttraumatic stress disorder in abused and neglected children. Am J Psychiatry 156:1223-1229

Wigger A, Neumann ID (1999): Periodic maternal deprivation induces gender-dependent alterations in behavioral and neuroendocrine responses to emotional stress in adult rats. Physiol Behav 66:293-302

Wilcox RA, Robinson TE, Becker JB (1986): Enduring enhancement in amphetamine-stimulated striatal dopamine release in vitro produced by prior exposure to amphetamine or stress in vivo. Eur J Pharmacol 124:375-376

Wise RA, Bozarth MA (1987): A psychomotor stimulant theory of addiction. Psychol Rev 94:469-492
Woolfolk DR, Holtzman SG (1995): Rat strain differences in the potentiation of morphine-induced analgesia by stress. Pharmacol Biochem Behav 51:699-703

Young EA, Abelson JL, Curtis GC, Nesse RM (1997): Childhood adversity and vulnerability to mood and anxiety disorders. Depress Anxiety 5:66-72

Yuferov V, Easterling KW, Schlussman SD, Mantsch JR, Kalinichev M, Ho A, Holtzman SG, Kreek MJ (2000): Maternal separation affects mRNA levels of the opioid system in adult rats subjected to restraint stress and tests of morphine antinociception. Philadelphia, PA, College on Problems of Drug Dependence Abstract.

Zimmerberg B, Shartrand AM (1992): Temperature-dependent effects of maternal separation on growth, activity, and amphetamine sensitivity in the rat. Devel Psychobiol 25:213-226 